\title{
Research on the Influence of Diversification Strategy Model on Enterprise Value Based on Principal-Agent Theory
}

\author{
Haixu Song ${ }^{1, a,{ }^{*}}$, Xiaodong $\mathrm{Li}^{1, \mathrm{~b}}$ and Xiaofeng Zhang ${ }^{1, \mathrm{c}}$ \\ ${ }^{1}$ SGCC Administrative Area, Future Science and Technology Park North Area, Beqijia Town, \\ Changping, Beiqijia, P. R. China \\ ashxstudent@126.com, blixiaodong@sgeri.sgcc.com.cn, \\ czhangxiaofeng@sgeri.sgcc.com.cn \\ ${ }^{*}$ Corresponding author
}

Keywords: Diversification Strategy; Change model; Enterprise Value.

\begin{abstract}
Based on the principal-agent theory, this paper studies the impact of diversification strategy model on Enterprise Value, using the data of listed companies in China from 2015 to 2016 as a sample. The results show that the diversification strategy change with the external M\&A model has higher enterprise value than internal development model. It is because that there're two-tier agency problems in diversification enterprises: agency problem between shareholders and top management, and agency problem between top management and business unit managers. And the agency problem is more serious under the internal change model. This conclusion enriches the theoretical research results of the impact of diversification strategy on enterprise value, and provides a new basis for the decision-making of listed companies and investors.
\end{abstract}

\section{Introduction}

Diversification strategy is one of the important growth strategies of an enterprise, and it has a long-term, overall and fundamental guiding role for enterprise development[1]. From a dynamic perspective, the diversification strategy belongs to a change, which involves not only the change of diversification degree, but also the change model.

The change model of diversification strategy mainly includes internal development model and external M\&A model. The internal development model, is a diversified realization pattern in which enterprises invest in production factors such as capital into new industries, and establish new organizations and business sites within the enterprise[2]. Because it is a diversified expansion based on the enterprises' own strength and resources, it generally has the advantages of low risk, strong planning and flexibility, and strong coordination of departments. The change can be developed gradually. At the same time, however, it also has some deficiency, such as slow speed and low entry barriers. Especially when the market develops rapidly, the internal development model may not catch up with the market development speed and miss the best opportunity[3].

The external M\&A model is a pattern in which companies adopt mergers or acquisitions to restructure or participate in other companies in other industries to achieve diversified expansion[4]. External M\&A models can usually be achieved through equity acquisitions, asset acquisitions or direct mergers. Compared with the internal development model, it has the advantages of rapid change and small barriers to entry. It enables enterprises to complete strategy adjustment, acquire the capabilities of operating new business quickly[5]. But at the same time the risk also exists, such as insufficient resources integration.

Different diversification strategy models both have obvious advantages and disadvantages, and their impact on enterprise value is also different. In view of this, this paper analyzes the impact of different diversification strategy models on enterprise value based on the principal-agent theory, providing support for enterprises. 


\section{Theoretical Analysis and Research Hypothesis}

\subsection{Analysis of the Impact of Diversified Change on Enterprise Value under Internal Development Model}

In a diversified enterprise, there are two-tier agency problems: agency problem between shareholders and top management, and agency problem between top management and business unit managers. In the process of diversification strategy change, the agency problems also exist, especially under internal development mode.

(1) Agency problem between shareholders and top management. When an enterprise expands through the internal development model, the organization structure often doesn't change greatly, except adding new business units. Hannan and Freeman (1984) call it "enterprise organization structure rigidity"[6]. Liu Haijian (2007) found that the enterprises organization structure rigidity include five dimensions: centralization, specialization, complexity, integration and institutionalization[7]. And centralization is the most obvious in the process of internal expansion. As the highest decision-making mechanism, the corporate governance structure is characterized by the stability and continuity of the shareholders and the top management. Without external interference, it will not be changed easily. This feature provides an opportunity for top management to implement a diversification strategy at their own discretion. Shleifer and Vishny (1989) found that when shareholders make decisions about whether entering a new industry and how to enter the new industry, top management can guide shareholders to invest in areas that the managers are familiar with or are good at[8]. And then The top management will become the actual controller of diversified strategic decision-making and implementation. In this situation, diversification strategy can not only create defense for themselves and reduce their own occupational risks, but also increase their reputation in the industry by managing larger companies. Yuan Chun et al (2010) found that the top management will affect diversification degree to hold more free cash flow[9]. Therefore, diversified change under the internal development model may produce more serious first-level agency problems, making capital investment exceed the optimal investment level which can lead to capital allocation efficiency not optimal.

(2) Agency problem between top management and business unit managers. The impact of the second-level agency problem is mainly reflected in the appointment of personnel. Zhao Shuming (2003) found that when an enterprise takes diversified expansion under the internal development model, business unit managers in new industries usually have two ways to hire[10]. One is to mobilize employees with certain competence within the company, one is to hire professionals from the labor market. If the enterprise adopts the former way, employees may be unfamiliar and unsuitable after becoming a business unit manager because that the industry is new for them[11]. And then employees will ask the top management for more funds to support business development, which may result in over-allocation of capital investment in this business unit. If the enterprise adopts the latter way, new employees and companies are an employment relationship based on the exchange of interests[12]. New employees may rely on their professional advantages to bargain with the top management on investment allocation issues, which may result in over-investment. Therefore, regardless of the type of appointment, the top management and the business unit manager may have a large conflict of interest, and the capital allocation efficiency may be not optimal under the internal development mode

\subsection{Analysis of the Impact of Diversified Change on Enterprise Value under the External M\&A Model}

The paper analyze external M\&A models on enterprise value from the two-tiered agency problem of diversified firms.

(1) Agency problem between shareholders and top management. M\&A is taken on the basis that the M\&A company (the company) and the target company (the new company entering the industry) reach an agreement on the price, personnel and so on. Luo Wenzhi et al. (2007) pointed out that the listed companies taking M\&A should not only obey the basic laws such as "The Company Law" "The 
Securities Law" as the same as the general corporates, but also obey the laws related property rights transfer and asset valuation, such as "The Antitrust Law" "The Anti-Unfair Competition Law"[13]. The law stipulates that mergers and acquisitions of listed companies should be reviewed and supervised by accounting firms, law firms, appraisal firms, the China Securities Regulatory Commission and so on. Listed companies must disclose relevant information promptly and objectively. Under this circumstance, the legal constraints make the diversification strategy change under the M\&A model more standardized. Except the game question between the internal shareholders and the top management, it also exists the transaction question between the merger company and the target company. The behavior of top management is limited by laws and regulations. Their actual control of the strategic change is declining, and the possibility of encroaching on shareholders' interests is also reduced. Moreover, even if the top management implements self-interested behavior, it may pay a higher price for it. Therefore, the top management may not easily use the diversification strategy to encroach on the interests of shareholders, and the possibility of decline in capital allocation efficiency may be reduced.

(2) Agency problem between top management and business unit managers. Mcintyre (2004) found that many M\&A contract terms stipulate that business unit managers in the M\&A company are often maintained by the original business managers of the target company[14]. It not only maintains the interests of the acquired units in personnel matters, but also facilitates the development of new business in the M\&A company.

The CEO of the company's management is often served by the CEO of the M\&A company. Business unit managers who want to bargain with top management may be affected by the fact that the CEO of their original target company no longer holds the highest position in the company. Therefore, the over-allocation of business units caused by the diversification strategy may be weakened, and the decline in capital allocation efficiency and enterprise value may also be suppressed to some extent.

\subsection{Comparative Analysis of the Impact of Diversified Transformation Models on Enterprise Value}

It can be seen from the above analysis that under the internal development model, the company's expansion is more flexible, and shareholders and top management will not be changed substantially. There is a greater possibility of serious agency conflicts among diversified enterprises. As a result, the efficiency of capital allocation declines, and further it causes a significant decline in enterprise value. The impact of diversification strategy changes under the internal development model on enterprise value may be negative. Under the external M\&A model, the enterprises are restrained by the laws and regulations, and diversification strategy changes will be more regulated and reviewed by regulators and intermediaries also. Moreover, the shareholders, the top management, and the business unit managers are mostly reorganized by the original organization personnel of the merger company and the target company. Each stakeholder will inevitably have a certain degree of strangeness in the initial stage of merger and acquisition, and thus mutual supervision will be generated. So the agency conflict may be relieved to a certain extent, the probability of capital allocation efficiency may lessen, and the negative impact on the enterprise value may also reduce. Therefore, compared with the internal development model, under the external M\&A model, the problems of excessive investment are smaller, and the capital allocation efficiency may be higher. Based on this, this paper proposes the hypothesis:

Hypothesis: In the case of the same change in the degree of diversification, enterprises that adopt the external M\&A model for diversification strategy changes have higher enterprise value than the internal development model. 


\section{Empirical Analysis}

\subsection{Sample selection and data source}

This paper selects companies with diversification strategy change of China's A-share listed companies in 2015-2016. After removing financial and insurance companies, companies with major issues such as ST or PT, and companies with incomplete data, this paper has a total of 216 diversification strategy change samples finally. Among them, there are 85 external M\&A models and 161 internal development models.

\subsection{Variable Definition and Empirical Model Design}

Enterprise value is measured by annual stock excess return (Bhr). For the diversification strategy change under the M\&A model, the stock excess return is calculated in the following 12 months and 24 months after the month of the M\&A announcement. For the diversification strategy change under the internal development model, the stock excess return is calculated in the following 12 months and 24 months after the end day of the year carrying out diversification strategy. Because the process of diversification change is gradual, and it is impossible to obtain accurate changes through public information.

Diversification strategy change is measured by two dimensions: the change model and the degree of change. The change model is measured based whether the enterprise adopts the external M\&A model. If the enterprise adopts the external M\&A mode, the value is 1 , otherwise it is 0 . The degree of change is measured by the change of diversified entropy $(\triangle \mathrm{Div})$.

Other variables include return on equity (Roe), asset-liability ratio (Lev), growth rate of main business income (Grow), shareholding ratio of the largest shareholder (Shr) and company size (Size).

Table 1. Definition of variables

\begin{tabular}{c|c|c}
\hline Name & Symbol & Description \\
\hline Diversification strategy change model & change & $\begin{array}{c}\text { If the enterprise adopts the external M\&A mode, the } \\
\text { value is 1, otherwise it is } 0 .\end{array}$ \\
\hline The degree of change & $\triangle$ Div & the change of diversified entropy \\
\hline Capital investment ratio & Inv & Capital investment divided by total assets \\
\hline Return on equity & Roe & Net profit divided by net assets \\
\hline Asset-liability ratio & Lev & Total liabilities divided by total assets \\
\hline Growth rate of main business income & Grow & $\begin{array}{c}\text { The addition of main business income divided by the } \\
\text { above main business income }\end{array}$ \\
\hline Shareholding ratio of the largest shareholder & Shr & $\begin{array}{c}\text { Number of shares held by the largest shareholder } \\
\text { divided by total number of shares of the company }\end{array}$ \\
\hline Company size & Size & Ln(the total assets) \\
\hline
\end{tabular}

The model among diversification strategy, capital allocation efficiency and enterprise value are as follows. And a1 is used to test the impact of the diversification strategy change model on enterprise value. And a4 is used to test the impact of diversification strategy change model on enterprise value through capital allocation.

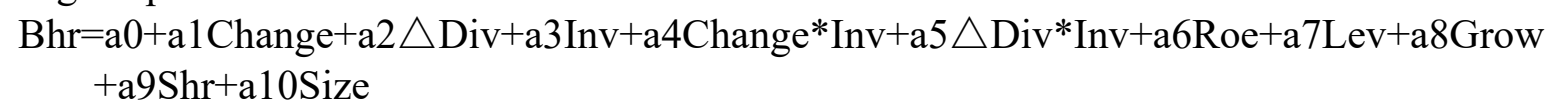

\subsection{Result analysis}

\subsubsection{Descriptive statistical analysis}

The paper takes Descriptive statistics on the enterprises value in different periods after the diversification strategy change, as shown in Table 1. The company's average excess return in 12 months after the diversification strategy change is 0.038 , and the one in 24 months is 0.097 . The excess return is rising year by year. The difference of excess return between the internal development model and the external M\&A model is -0.038 in 12 months after the diversification strategy change, and it is significant at the 0.1 level. At the same time, the difference is -0.066 in 24 months and is 
significant at the 0.05 level. It means that the enterprises which adopt the internal development model for diversification strategy change have lower enterprise value than the external M\&A model, and this difference becomes more and more obvious with time, initially supporting hypothesis.

Table 2. Enterprise value after diversification strategy change

\begin{tabular}{c|c|c|c|c}
\hline & Overall & Internal model & M\&A model & Difference \\
\hline Bhr(in 12 mounth) & 0.038 & 0.021 & 0.059 & $-0.068^{*}(1.87)$ \\
\hline Bhr(in 24 mounth) & 0.097 & 0.059 & 0.125 & $-0.066^{* *}(-2.22)$ \\
\hline \multicolumn{2}{l}{ Notes: ${ }^{*}$ means $\mathrm{p}<0.05,{ }^{*}$ means $\mathrm{p}<0.1}$.
\end{tabular}

\subsubsection{Regression analysis}

In order to examine the impact of the diversification strategy change model on enterprise value, the enterprise value of 12 months and 24 months after the diversification strategy change is taken as the explanatory variable, to explore whether the diversification strategy change model will have an impact on enterprise value.

When the Bhr (in 12 month) is the explanatory variable, the adjusted $\mathrm{R}^{2}$ of the model is 0.39 and the $\mathrm{F}$ value is 23.3 , which is significant. Vif is 1.68 , which is far less than 10 . The model basically does not have multiple collinearity problems. Diversification strategy change model and the excess return rate are significantly positively correlated at the 0.1 level. The capital investment and the excess return rate are significantly negatively correlated at the 0.05 level. The cross-term of diversification strategy change model and capital investment has positive impact on of excess return rate at the 0.05 level. It means that the diversification strategy change under the external M\&A model can alleviate the negative impact of capital investment on enterprise value. The result shows that the enterprise value of diversification strategy change under the external M\&A model is higher than the internal development model, supporting Hypothesis.

When the Bhr (in 24 month) is the explanatory variable, the adjusted $\mathrm{R}^{2}$ of the model is 0.32 and the $\mathrm{F}$ value is 26.7 , which is significant. Vif is 1.82 , which is far less than 10 . The model basically does not have multiple collinearity problems. Diversification strategy change model and the excess return rate are significantly positively correlated at the 0.05 level. The capital investment and the excess return rate are significantly negatively correlated at the 0.05 level. The cross-term of diversification strategy change model and capital investment has positive impact on of excess return rate at the 0.05 level, further supporting Hypothesis.

Table 3. Regression Analysis of Diversification Strategy Change and Enterprise Value

\begin{tabular}{|c|c|c|}
\hline Variables & Bhr(in 12 month) & Bhr(in 24 month) \\
\hline Constant & $\begin{array}{c}-1.323 * * \\
(-2.07) \\
\end{array}$ & $\begin{array}{r}-0.439 * \\
(-1.81) \\
\end{array}$ \\
\hline Change & $\begin{array}{c}0.045^{*} \\
(1.91) \\
\end{array}$ & $\begin{array}{c}0.072 * * \\
(2.32)\end{array}$ \\
\hline$\triangle \mathrm{Div}$ & $\begin{array}{c}-0.115 * * * \\
(-2.57)\end{array}$ & $\begin{array}{c}-0.339 * * \\
(-2.29)\end{array}$ \\
\hline Inv & $\begin{array}{c}-0.312 * * \\
(-2.18)\end{array}$ & $\begin{array}{c}-1.142 * * \\
(-2.23)\end{array}$ \\
\hline Change*Inv & $\begin{array}{c}0.272 * * \\
(2.16)\end{array}$ & $\begin{array}{c}0.476 * * \\
(2.33)\end{array}$ \\
\hline$\triangle \mathrm{Div}^{*} \operatorname{Inv}$ & $\begin{array}{c}-2.786 * * \\
(-2.38) \\
\end{array}$ & $\begin{array}{c}-1.867^{* *} \\
(2.28)\end{array}$ \\
\hline Control variables & - & $\longrightarrow$ \\
\hline Vif & 1.68 & 1.82 \\
\hline Adj-R2 & 0.39 & 0.32 \\
\hline F-value & $23.3^{* * *}$ & $26.7 * * *$ \\
\hline
\end{tabular}


The external M\&A model will bring higher capital allocation efficiency and enterprise value than the internal development model, whether it is in the short-term time (12 months) or the longer-term (24 months) after the diversification strategy change.

\section{Conclusions}

Based on the principal-agent theory, this paper takes the data of listed companies in China from 2015 to 2016 as a sample, and studies the impact of diversification strategy change models on enterprise value. In the case of the same change in the degree of diversification, the enterprise value of the diversification strategy change under the external M\&A model is higher than the internal development model. This conclusion starts from the diversification strategy model, broadening the ideas and achievements of research about diversification strategy and enterprise value. This paper finds that the external M\&A model are mostly implemented under certain laws and regulations, and the management's rights will be constrained. So the agency conflicts among the various stakeholders in diversified enterprise will be alleviated. At last the value of M\&A model is higher than the internal development model.

Therefore, the conclusion of this paper has important implications in both theory and practice. The theoretical revelation is that in the value analysis of diversified enterprises, we must not only consider the impact of diversification on enterprise value in a static environment, but also consider the impact of diversification strategy change model on enterprise value in a dynamic environment. The meaning of the diversification strategy includes two levels. One refers to the strategic state of the enterprise from a static perspective, i.e., the degree of diversification, and the other refers to the strategic change of the enterprise from a dynamic perspective, involving the degree and model of change. The strategic state is the basis of strategic change. Strategic change is the way to form a new strategic state. The state and change are interdependent, cross-cutting and inseparable. Therefore, the diversification strategy that investors pay attention to is an overall activity. The two dimensions of degree and model exist at the same time, which jointly determine the benefits or losses that investors ultimately obtain. If we only analyze from a static perspective, we cannot reflect the diversification strategy model, nor fully understand the effect of diversification strategy on enterprise value. Therefore it can reveal impact mechanism of diversification strategy on enterprises value more deeply.

The practical revelation is that companies and investors should pay more attention to the impact of diversification strategy change on enterprise value. For the enterprise, the diversification strategy is an overall strategy, which is an enterprise continuously adjusts and changes based on certain transformation models, according to the future development goals and the external environment. Even if the degree of diversification is the same, the value performance will be very different due to the different implementation models. Therefore, in the process of strategy implementation, enterprises should choose the appropriate model. For investors, strategy change is the focus of them. So investors should be keenly aware of the strategy change dynamics of enterprises and adjust their investment strategies timely, to realize the investment income more fully.

\section{References}

[1] H. L. Lan, Research on Strategic Management of Diversified Enterprises in China. Economic science press, pp.3-5, 2008.

[2] D. Mei, Governance Mechanism and Over-investment of State-owned Listed Companies. Journal of Shanghai Lixin University of Commerce, vol(4), pp.47-56, 2008.

[3] H. Gonenc, O. B. Kan, E. C. Karadagli, Business Groups and Internal Capital Markets. Emerging Markets Finance and Trade, vol.43(2), pp.63-81, 2007.

[4] S.M. Li, X.C. Zhou, Empirical Research on Corporate Characteristics, Industry Characteristics and M\&A Strategy Types. Management World, vol(3), pp.130-137, 2007. 
[5] R. C. Moyer, R. E. Chatfield, P. M. Sisneros, Security Analyst Monitoring Activity: Agency Costs and Information Demand. Journal of Financial and Quantitative Analysis, vol.24(4), pp.503-512, 1989.

[6] M.T. Hannan, J. Freeman, Structural Inertia and Organizational Change. American Sociological Review, vol.49(2), pp.149-164, 1984.

[7] H. J. Liu, The rigid characteristics of enterprise organizational structure and its impact on strategic change. Science of Science and Management of S.\&.T. vol(3), pp.126-132, 2007.

[8] A. Shleifer, R. W. Vishny, Management Entrenchment: The Case of Manager-Specific Investments. Journal of Financial Economics, vol.25(1), pp.123-139, 1989.

[9] C. Yuan, S. M. Liu, Y. Chen, Major shareholder control, diversification and cash holding value. China Industrial Economic, vol(4), pp.141-150, 2010.

[10]S. M. Zhao, Research on Human Resource Management Strategy of Chinese Enterprise Group. Nanjing University Press, pp.56-59, 2003.

[11]X.Q. Du, Q. Zeng, Y. J. Du, Political connections, over-investment and company value - based on empirical data from state-owned listed companies. Journal of Financial Research, vol(8), pp. 93-110, 2011.

[12]A. D. Motta, Managerial Incentive and Internal Capital Market. Journal of Finance, vol.58(3), pp. 1193-1219, 2003.

[13]W. Z. Luo, K. X. Wang, H. B. Dong, W. Jiao, Listed company merger and acquisition legal practice. Law Publisher, pp.77-79, 2007.

[14]T. L. Mcintyre, A Model of Levels of Involvement and Strategic Roles of Human Resource Development (HRD) Professionals as Facilitators of Due Diligence and the Integration Process. Human Resource Development Review, vol.3(2), pp.173-182, 2004. 